\title{
An insight in decoding the multifarious and splendid role of microorganisms in crop biofortification
}

\author{
Viabhav Kumar Upadhayay ${ }^{1}$, Ajay Veer Singh $^{1}$ and Navneet Pareek $^{2}$ \\ ${ }^{1}$ Department of Microbiology, College of Basic Sciences and Humanities, ${ }^{2}$ Department of Soil \\ Science, College of Agriculture, G. B. Pant University of Agriculture and Technology, \\ Pantnagar (U. S. Nagar)-263145, Uttarakhand, India \\ *Corresponding author
}

\section{A B S T R A C T}

Agronomic practices of present era mainly focused on huge production of cereals and other food crops in more sustainable mode for challenging incessantly raising global population. However, rigorous cropping patterns and other environmental factors resulted into reduce micronutrients concentration in crop plants. Large human population relies on

Keywords

Crop

biofortification,

Plant growth promoting bacteria, Micronutrients,

Zinc solubilization, Siderophore production

\section{Article Info}

Accepted:

20 May 2018

Available Online:

10 June 2018 such crops for staple food engenders risk of micronutrient deficiency, also narrated as 'hidden hunger'. Then the strategy of biofortification is a leading solution to counteracting the problems of micronutrient deficiency in various crops. Agronomic, breeding and intervention through biotechnology are main approaches of biofortification for delivering important micronutrients ( $\mathrm{Zn}, \mathrm{Fe}, \mathrm{Se}$ and $\mathrm{Mn}$ ) with increase concentration in various crops, but these approaches are expensive, laborious and slower. However, application of microorganisms represents inexpensive and alternative approach of biofortification with ultimate solution for assisting plants by enhancing their growth with increase micronutrients concentration. Microorganisms have the capacity to solubilize zinc through wide arrays of mechanisms including acidification of nearby soil by organic acid synthesis, productions of siderophore, oxido-reductive system on cell membrane and chelated ligands. Inoculation of microorganisms especially plant growth promoting bacteria, is a better strategy making increase availability of micronutrients in various edible parts of plants. This review is focus to confer an insight on exploiting of microorganisms for increased micronutrient content in plants, using research studies conducted from last few decades to now, and presenting view on using such microorganisms as effective bioinoculant to drive biofortification of food crops in more eco-friendly impendent to improve sustainable agriculture.

\section{Introduction}

To address the problem of micronutrients deficiency in food crops, biofortification strategy is appreciable solution which consigns proper level of essential nutrients in several edible parts of plants. Adverse environmental factors obstruct the uptake of micronutrients from soil to plants, and therefore inadequate amount of micronutrients affects the plant growth and development. Deficiency of micronutrients (zinc, iron, 
selenium, copper, manganese and vitamins) in both humans and plants is narrated as 'hidden hunger' (de Valenca et al., 2017) and set the threat of malnutrition among global human population. The goal of current agriculture system is to produce nutritious safe food crops with elevated level of micronutrients in the edible part of plants. Major human population is heavily dependent on crop based foods for basic diet, and having diet with inadequate level of essential micronutrients engenders serious health related issues in human beings. Therefore, adopting biofortification strategy provide better solution for producing crops with enhanced level of required micronutrients. Most literatures mainly suggested biofortification of food crops by three different ways: I) agronomic biofortification, II) breeding approach and III) genetic modifications. However, these approaches of agronomic and genetic biofortification to augment micronutrient concentration in crops for alleviating micronutrient malnutrition is considered to be lucrative and inappropriate in developing countries where rural population is most common (Mayer et al., 2008). Moreover, rigorous application of chemical fertilizers presents several nuisance scenarios by disrupting soil microbial ecology and demolishing soil fertility, and ultimately drastic effects on both crop production and human health have been observed. Therefore, obvious demand arises for exploring another cost effective alternative strategies instead of genetic and agronomic approaches for fulfilling the aim of biofortification. Using of microorganisms, especially plant growth promoting microorganisms is an alternative approach for biofortification and better substitute of chemical fertilizers (Singh et al., 2017). Moreover, utilization of plant growth promoting rhizobacteria as bioinoculants presents a low-cost and sustainable option for augmenting the micronutrient concentrations in plants (Shaikh and Sharaf, 2017). Soil dwelling plant growth promoting microbiome maintains soil health, and facilitate the conversion of complex mixtures of micronutrients into simpler form which are ultimately uptake by plants (Singh and Singh, 2017; Shah et al., 2018; Prasad et al., 2016). Plant associated bacteria stimulate the growth of host plant through several ways such as increase mobility, uptake, and enrichment of nutrients in plants (Prasanna et al., 2016; Singh and Prasad, 2014). Plant growth promoting bacteria/rhizobacteria (PGPB/R) enhance crop production through various mechanisms namely biological nitrogen fixation, solubilization of insoluble minerals (like $\mathrm{P}, \mathrm{Zn}, \mathrm{Ca}$ etc.), production of phytohormones and biocontrol (Glick et al., 1999; Singh et al., 2010, 2010a, 2010b, 2011; Singh and Goel, 2015). Microorganisms can also influence nutrient availability through exhibiting various characteristics including chelation, solubilization and oxidation or reduction (Khan, 2005; Singh et al., 2013, 2018). Soil and rhizosphere associated microorganisms helps in improved nutrient acquisition of essential micronutrients from soil system to various portions of plants, and thus microbial assisted precise nutrient acquisition approach make microorganisms suitable candidates for crop biofortification with require nutrient elements essentially zinc $(\mathrm{Zn})$, iron $(\mathrm{Fe})$ and selenium $(\mathrm{Se})$. Diverse form of microbiome including bacteria, cyanobacteria and fungi can be considered for efficient plants growth with deriving increased concentration of nutrients in crops at significant level, as achieved by genetic and agronomic based biofortification. However, plant growth promoting microbial entities are minutely explored for biofortification approach and they are needed to be put into the category of natural biofortification agent to develop biofortified crops. Present review is focused on role and application of microorganisms for decoding their admirable competence for biofortification of plants 
especially food crops with selected micronutrients.

Major micronutrients and effects of their deficiency

High existence of micronutrient deficiency results in extensive disease burden in low and middle income countries (Black, 2014), and hence present devastating influence on human health. According to the United Nations System Standing Committee on Nutrition (UNSSCN), (2004) micronutrients malnutrition directly or indirectly associated with more than $50 \%$ of all child mortality and also associated with most foremost risk factors for maternal mortality. Iron $(\mathrm{Fe})$, zinc $(\mathrm{Zn})$ and selenium (Se) are measured as chief micronutrients and for maintaining life processes they are essentially required through diet. Deficiency of one or more micronutrients presents health related issues express in variety of diseases. Iron $(\mathrm{Fe})$, a fourth most abundant and essential microelement on the earth crust (Tripathi et al., 2015), which takes parts in various cellular processes (Puig et al., 2005). Fe deficiency cause chlorosis in plants (Brown, 1961) and considered as major limitation for crop yield and which ultimately affects human health via food-chain, particularly to those people whose diets mostly rely on plant resources (Abadia et al., 2011). Situation of iron deficiency is the common factor for causing nutritional anemia (Hurtado et al., 1999) which are also associated with impaired neurocognitive development and as well impaired immune factions in children (Murray-Kolb, 2013). The micronutrient zinc $(\mathrm{Zn})$ is vital for all organisms (Broadley et al., 2007) and plays key structural roles in several proteins (Hershfinkel, 2005). Zinc deficiency may engenders a number of human health related issues such as retarded growth, deferred wound healing, diarrhea, skeletal abnormalities, increased risk of abortion
(Salgueiro et al., 2000), impairments of physical growth and greater risk of various infections (Hotz and Brown, 2004). Another example of profound dietary nutrient is selenium (Se), which involved in wide range of metabolic pathways including antioxidant defense and thyroid hormone metabolism (Rayman, 2012). Selenium (Se) deficiency may associated with a number of health disorders such as heart diseases, hypothyroidism, reduced male fertility, weakened immune system and increased risk of cancer, infections, oxidative stress-related conditions and epilepsy (Rayman, 2012; Hatfield et al., 2014).

\section{Strategies for biofortification}

Importance of micronutrients is well understood and it is always advisable to consume foods that are nutrient rich for maintaining the health. Food is a basic source for micronutrients intake, and it is prerequisite to produce the food crops with elevated level of micronutrients concentration. Therefore, biofortication is a mean through which nutrient elements level could be increased directly in food crops through adapting agriculturally or core science based approaches. Biofortification strategies such as agronomic, plant breeding, genetic engineering and application of microbial inoculants are the key methods for improving nutritional content of plants. 'Agronomic biofortification' is the method for application of nutrient-rich fertilizers to soil or on foliage to increase the micronutrients level in edible part of the crops and consequently enhance the consumption of necessary micronutrients by consumers (Carvalho and Vasconcelos, 2013). Important approach for biofortification is "plant breeding" practiced by farmers for hundred of years where conventional plant breeding is designated to the crossing of plants to yield descendants with characters of both parents (Garcia-Casal et al., 2016) and thus 
this technique can be employed to produce descendents with admirable level of necessary nutrient elements. Rice varieties possessing high proportions of $\mathrm{Fe}$ and $\mathrm{Zn}$ were crossed with high-yielding rice varieties to produce descendants with both characteristics such as high yield and enhanced level of micronutrients (Khush, 2003). Biofortification made through "genetic modification" takes less time to generate crops those expresses in a stable way the trait of interest (e.g. nutritional content) and allows the transfer of particular genes or gene of interest (Garcia-Casal et al., 2016). To exploit microbial inoculants for biofortification expresses cost effective approach and gives sustainable solution for enhanced micronutrient concentration in plants in environment friendly manner. Beneficial soil microorganisms make possible nutrients availability to plants through numerous mechanisms such as atmospheric nitrogen fixation, solubilizing the nutrients fixed into the soil, and by producing phytohormones (Yao et al., 2008;). Such microorganisms make assure for further enhancement of micronutrients in plants, as they play a key role in organic material mineralization and as well as transforming inorganic nutrients (Rana et al., 2012a).

\section{Mechanistic insight intended for executing microbial based biofortification}

Soil and rhizospheric region is main hub for innumerable microorganisms express various relation with plants and superiorly influence the plant growth and development. Microbial influence on micronutrients mobility is a significant module for biofortifying the food crops with several trace elements ( $\mathrm{Zn}, \mathrm{Fe}$ and Se). Microbial exudates carried out several practices such as chemical transformation, chelation and protonation for mobilization of trace elements. The influence of bacterial and fungal activity on trace elements mobility and its use for bioremediation has been reviewed by Gadd (2004), where the contemporary knowledge on potential mechanisms of trace element mobilization by rhizobacteria has been summarized. Production of organic acid for $\mathrm{Zn}$ mobilization and synthesis of siderophore for $\mathrm{Fe}$ chelation through soil microorganisms are well established facts for transferring these nutrients in plants. Extensive persistence of zinc deficiency in crops due to inadequate supply of $\mathrm{Zn}$ from soil in to plants increased jeopardy of malnutrition at globe level. Zinc deficiency is expected to increase from $42 \%$ to $63 \%$ by 2025 due to continuous depletion of soil fertility (Singh, 2009) and presents serious concern about zinc deficiency in crops and as well humans. Soil is rich with plenty of zinc, but its deficiency prevailed in crops due to presence of unavailable fraction of $\mathrm{Zn}$ (Sunithakumarai et al., 2016). Microorganisms employ the strategies for solubilization of $\mathrm{Zn}$ and other nutrients through production of wide range of organic acids. Organic acids are mainly $\mathrm{CHO}$ containing compounds characterized by the occurrence of one or more carboxyl groups with a maximum molecular weight of 300 daltons (Jones, 1998). Organic acids secreted by microflora increase soil $\mathrm{Zn}$ availability by sequestering cations and by reducing rhizospheric $\mathrm{pH}$. However, $\mathrm{Zn}$ solubility increases with decrease in $\mathrm{pH}$ and its activity refuses upon precipitation as carbonate, hydroxide, phosphate and silicate at slightly acid to alkaline $\mathrm{pH}$ (Baruah and Barthakur, 1999). The Zn solubilizing Bacillus strains has been found to solubilize unavailable form of zinc through production of amino acid, chelating ligands, vitamins and phytohormones, oxido-reductive systems, proton extrusion and secretion of organic acids (Saravanan et al., 2003). Plants incorporate iron from bacterial siderophores through different mechanisms such as chelate and release of iron, the direct uptake of siderophore-Fe complexes and by ligand exchange reaction (Schmidt, 1999). Hence, 
association of siderophore producing microorganisms with plants become important for facilitating iron into plants, especially in iron deficient conditions. Carrillo-Castañeda et al., (2002) reported positive effects of siderophore producing Pseudomonas, Rhizobium and Azospirillum on alfalfa plantlet growth with special reference to increased germination as well as the root and stem dry weight after the inoculation grown in iron limited cultures. Mung bean plants inoculated with the siderophore-producing Pseudomonas strain GRP3 under iron scarce conditions showed less chlorotic symptoms and enhanced chlorophyll content when compared to uninoculated plants (Sharma et al., 2003). Both organic and inorganic forms of Se are exist in agroecosystem, where inorganic form of Se presents four oxidation states denoted as $\mathrm{Se}^{2-}$ (selenide), $\mathrm{Se}^{0}$ (elemental $\mathrm{Se}$ ), $\mathrm{Se}^{4+}$ (selenite) and $\mathrm{Se}^{6+}$ (selenate) (FernandezMartinez and Charlot, 2009). In general, bacteria have the ability to reduce oxidized and methylated $\mathrm{Se}$ oxyanions to some different Se-compounds. The reduction processes have been illustrated as the capacity of these microorganisms to convert the $\mathrm{Se}^{6+}$ and $\mathrm{Se}^{4+}$, to $\mathrm{Se}^{0}$ and finally generate $\mathrm{Se}$ methylated compounds (Losi and Frankerberger, 1997) and organic Se compounds (SeMet and SeMeSeCys) (Duran et al., 2015) and provide usable form of Se in agriculture system.

\section{Biofortification strategies through microorganisms}

\section{Zinc}

Application of $\mathrm{Zn}$ fertilizers to various crops was promoted to tackle down the crisis of zinc scarcity, but their transformation to various unavailable forms depending upon soil types and chemical reactions (Gontia-Mishra et al., 2017) set forth a further issue of zinc deficit state. The unavailable $\mathrm{Zn}$ compound can be converted back to available form through bioaugmentation of microbial inoculants bearing the ability to solubilize insoluble $\mathrm{Zn}$ compounds (Saravanan et al., 2007). In the last few years, the ability to solubilize insoluble $\mathrm{Zn}$ compounds $\left[\mathrm{ZnO}, \mathrm{ZnCO}_{3}\right.$, $\left.\mathrm{Zn}_{3}\left(\mathrm{PO}_{4}\right)_{2}\right]$ by plant growth promoting rhizobacteria (PGPR) has been reported (Krithika and Balachandar, 2016; Saravanan et al., 2007). Bacteria isolated from rice rhizosphere solubilized zinc through lowering the $\mathrm{pH}$ of culture medium and used as a perspective inflictor of $\mathrm{Zn}$ biofortification of rice (Gontia-Mishra et al., 2017). Previous studies indicated that organic acids like gluconic acid, 2-ketogluconic acid, 5 ketogluconic acid and pentanoic acids are produced by microorganisms during $\mathrm{Zn}$ solubilization (Saravanan et al., 2007). Cyanobacterial inoculants on different maize hybrids also showed significant effect on zinc accumulation in flag leaf (Prasanna et al., 2015).

Tariq et al., (2007) have described the potential effect of Zn mobilizing PGPR which significantly alleviated the $\mathrm{Zn}$ deficiency symptoms and also increased the total biomass $(23 \%)$, grain yield $(65 \%)$, and harvest index in addition to increased $\mathrm{Zn}$ concentration in the grain of rice. Consortium of two bacillus species (Bacillus sp. SH-10 and B. cereus $\mathrm{SH}-$ 17) was marked as potent umpire to produce $\mathrm{Zn}$ fortified rice grains and showed highest zinc translocation index value (1.6 to 1.7 ) when compared with translocation index value of only $\mathrm{Zn}$ and consortium of $\mathrm{Zn}$ and bacterial strains (Shakeel et al., 2015).

Endophytic fungus $P$. indica under supplemented concentration of $10 \mathrm{mg} / \mathrm{l} \mathrm{Zn}$ significantly increased leaf $\mathrm{Zn}$ concentrations (7.6 fold) of lettuce plant with enhanced chlorophyll under greenhouse conditions and proved its representation for biofortification (Padash et al., 2016). 


\section{Iron}

Microorganisms also played the role of biofortifying tool for enhancing Fe content in palatable crops as suggested by various literatures. Siderophore producing microorganisms can be suitable candidates for iron biofortification as they provide additional iron availability to plants. Various plant growth promoting bacteria especially Enterobacteria sp, Pseudomonas putida and other bacterial strains potentially doubled iron content in rice grain with enhanced efficiency of $\mathrm{Fe}$ translocation from root to shoot and grains (Sharma et al., 2013), and thus presented event of strong application of plant growth promoting bacteria for $\mathrm{Fe}$ biofortification.

Inoculation with Trichoderma asperellum significantly increased the Fe concentration in wheat plants gown on Fe deficient calcareous medium and revealed a positive effect of this fungal organism on Fe nutrition in wheat (de Santiago et al., 2011). Increased concentration of $\mathrm{Fe}$ in different parts of chickpea plants (grains, shoots and roots) were reported after inoculation with PGPRs along with $\mathrm{Fe}$, and provided rhizobacterial based cost effective strategy for improving the $\mathrm{Fe}$ content in chickpea (Khalid et al., 2015).

\section{Selenium}

Selenium ( $\mathrm{Se}$ ) is considered as an essential micronutrient because of its antioxidant capacity and positive effects on human health (Cartes et al., 2005). The main source of Se for humans and animals is the soil-plant system, and a mineral imbalance can lead to Se-deficient food with consequences for human and animal nutrition (Govasmark and Salbu, 2011). In general, soils around the world have little Se quantities. Therefore, agronomic Se fortification by using inorganic Se source is a current technology in order to maintain optimizes level of Se status in human diet for reducing chronic disease risks (Bañuelos et al., 2016). The promising strategy for selenium biofortification was set in wheat through co-inoculation of selenobacteria mixture (Stenotrophomona sp. B19, Enterobacter sp. B16, Bacillus sp R12. and Pseudomonas sp. R8) and arbuscular mycorrhizal fungi (Glomus claroideum), and produced Se enriched wheat grains (up to $23 \%$ increased selenium content) for supplementing foods for human consumption (Duran et al., 2013). Duran et al., (2014) reported the potential use of three endophytic bacterial strains such as Bacillus, Klebssiella and Acinetobacter for selenium biofortifcation of wheat plants. Another study showed coinoculation of endophytic selenobacteia and AM fungus Rhizophagus-intraradices enhanced the Se content in lettuce plant and protected plants against drought stress conditions (Duran et al., 2016). These studies set forth the beneficial effect of symbiotic interacted selenobacteria and AM fungi for micronutrient biofortification of food crops. Bacillus cereus-YAP6 and Bacillus licheniformis-YAP7 increased Se uptake by wheat plants, and high concentration of Se was reported in Stem (375\%) followed by kernel (154\%), (Yasin et al., 2015) and determine the role of Bacillus for the selenium biofortification.

\section{Biofortification with other micronutrients}

Besides the $\mathrm{Fe}$ and $\mathrm{Zn}$, other important micronutrients are $\mathrm{Mn}$ and $\mathrm{Cu}$ which are essential for plants and animals. Increasing the micronutrient density of staple crops or biofortification can play a vital role in improving human nutrition on a global scale (Rana et al., 2012b). Mn deficiency is reported worldwide and differences in Mn efficiency among the crops are related to their ability to affect the solubility of $\mathrm{Mn}$ in the rhizosphere (Hassan Sayyari-Zahan et al., 2009). 
The availability of $\mathrm{Mn}$ in the rhizosphere is affected by several factors including redox condition and $\mathrm{pH}$, moisture, temperature and concentrations of other nutrients and heavy metal in soil solution. $\mathrm{Mn}^{4+}$ is the main oxidized form of $\mathrm{Mn}$ that exists in oxidized soil and considered as low soluble mineral pryolusite. Some rhizobacteria such as Bacillus, Pseudomonas and Geobacter reduce oxidized $\mathrm{Mn}^{4+}$ to $\mathrm{Mn}^{2+}$, which is metabolically useful for plants (Dotaniya et al., 2015). Mn reducing bacteria (Pseudomonas sp.) and fungi (Gaeumannomyces graminis) play an important role in enhancing $\mathrm{Mn}$ availability and crop uptake from the soil (St. Clair and Lynch, 2010). The microbial strains Providencia sp. (PW5) enhanced the Mn uptake and brought about a $36.7 \%$ increase in $\mathrm{Mn}$ content in wheat as compared to $\mathrm{N}_{60} \mathrm{P}_{60} \mathrm{~K}_{60}$ fertilizer control (Rana et al., 2012b).

In conclusion, food based crops with enhanced micronutrients concentration are required globally for eradicating hidden hunger. Plant associated microorganisms reside on soil and root interface and commence enhance uptake of macro as well micro nutrients for plants vitality. Various microorganisms efficient for siderophore production and zinc soulubilization were considered for boosting $\mathrm{Fe}$ and $\mathrm{Zn}$ in food crops, respectively. Plant growth promoting microorganisms were found to be capable to significantly augment zinc and iron content in rice and wheat, which are globally required in major food crops where the crops containing less concentration of micronutrients. Microbial inoculants established their potent role for biofortification and lessen the dependency on costlier approaches such as agronomic intervention and genetic modification for enhancing micronutrients concentration in edible part of crops. Multiple traits of plant growth promotion with various nutrients acquisitions processes made microorganisms able to formulate biofortification strategy. Improved content of micronutrients in crops in response to bioinoculants confirm trueness of microorganisms as biofortifier agents.

\section{References}

Abadía, J., Vázquez, S., Rellán-Álvarez, R., El-Jendoubi, H., Abadía, A., ÁlvarezFernández, A. and López-Millán, A. F. 2011. Towards a knowledge-based correction of iron chlorosis. Plant Physiology and Biochemistry, 49(5): 471-482. doi:10.1016/j.plaphy.2011.01.026

Bañuelos, G. S., Arroyo, I. S., Dangi, S. R. and Zambrano, M. C. 2016. Continued Selenium Biofortification of carrots and broccoli grown in soils once amended with Se-enriched S. pinnata. Frontiers in Plant Science. 7:1251. doi:10.3389/fpls.2016.01251

Baruah, T.C. and Barthakur, H.P. 1999. In: A Textbook of Soil Analysis. Vikas publishers, New Delhi, India, pp. 193196.

Black, R. E. (2014). Global distribution and disease burden related to micronutrient deficiencies. In Nestle Nutrition Institute Workshop Series. 78: 21-28. https://doi.org/10.1159/000354932

Broadley, M. R., White, P. J., Hammond, J. P., Zelko, I. and Lux, A. 2007. Zinc in plants. New Phytologist. 173(4). 677702. doi:10.1111/j.14698137.2007.01996.x

Brown, J. C. 1961. Iron Chlorosis in Plants. Advances in Agronomy, 329-369. doi:10.1016/s0065-2113(08)60963-3

Carrillo-Castañeda, G., Juárez Muños, J., Peralta-Videa, J., Gomez, E., Tiemannb, K., Duarte-Gardea, M. and GardeaTorresdey, J. 2002. Alfalfa growth promotion by bacteria grown under iron 
limiting conditions. Advances in Environmental Research, 6(3): 391-399. doi:10.1016/s1093-0191(02)00054-0

Cartes, P., Gianfreda, L. and Mora, M. 2005. Uptake of selenium and its antioxidant activity in ryegrass when applied as selenate and selenite forms. Plant and Soil. 276: 359. doi:10.1007/s11104-0055691-9

Carvalho, S. M. and Vasconcelos, M. W. 2013. Producing more with less: Strategies and novel technologies for plant-based food biofortification. Food Research International. 54(1): 961-971. doi:10.1016/j.foodres.2012.12.021

de Santiago, A., Quintero, J. M., Avilés, M. and Delgado, A. 2011. Effect of Trichoderma asperellum strain T34 on iron, copper, manganese, and zinc uptake by wheat grown on a calcareous medium. Plant and Soil. 342 (1-2): 97104. doi:10.1007/s11104-010-0670-1

de Valença, A., Bake, A., Brouwer, I. and Giller, K. 2017. Agronomic biofortification of crops to fight hidden hunger in sub-Saharan Africa. Global Food Security. 12: 8-14. doi:10.1016/j.gfs.2016.12.001

Dotaniya, M. L. and Meena, V. D. 2015. Rhizosphere effect on nutrient availability in soil and its uptake by plants: A Review. Proceedings of the National Academy of Sciences. India Section B: Biological Sciences. 85(1): 1-12. doi:10.1007/s40011-013-0297-0

Durán, P., Acuña, J.J., Armada, E., LópezCastillo, O.M., Cornejo, P., Mora, M.L. and Azcón, R. 2016. Inoculation with selenobacteria and arbuscular mycorrhizal fungi to enhance selenium content in lettuce plants and improve tolerance against drought stress. Journal of soil science and plant nutrition. 16(1): 201-225. https://dx.doi.org/10.4067/S071895162016005000017
Durán, P., Acuña, J. J., Jorquera, M. A., Azcón, R., Paredes, C., Rengel, Z. and De la Luz Mora, M. 2014. Endophytic bacteria from selenium-supplemented wheat plants could be useful for plantgrowth promotion, biofortification and Gaeumannomyces graminis biocontrol in wheat production. Biology and Fertility of Soils. 50(6): 983-990. doi:10.1007/s00374-014-0920-0

Durán, P., Acuña, J., Gianfreda, L., Azcón, R., Funes-Collado, V. and Mora, M. 2015. Endophytic selenobacteria as new inocula for selenium biofortification. Applied Soil Ecology, 96: 319-326. doi:10.1016/j.apsoil.2015.08.016

Durán, P., Acuña, J., Jorquera, M., Azcón, R., Borie, F., Cornejo, P. and Mora, M. 2013. Enhanced selenium content in wheat grain by co-inoculation of selenobacteria and arbuscular mycorrhizal fungi: A preliminary study as a potential Se biofortification strategy. Journal of Cereal Science. 57(3): 275-280.

doi:10.1016/j.jcs.2012.11.012

Fernández-Martínez, A. and Charlet, L. 2009. Selenium environmental cycling and bioavailability: a structural chemist point of view. Reviews in Environmental Science and Bio/Technology. $\quad 8(1): \quad 81-110$. doi:10.1007/s11157-009-9145-3

Gadd, G. M. 2004. Microbial influence on metal mobility and application for bioremediation. Geoderma. 122(2-4): 109-119.

doi:10.1016/j.geoderma.2004.01.002

Garcia-Casal, M. N., Peña-Rosas, J. P., Pachón, H., De-Regil, L. M., Centeno Tablante, E. and Flores-Urrutia, M. C. 2016. Staple crops biofortified with increased micronutrient content: effects on vitamin and mineral status, as well as health and cognitive function in the general population. Cochrane Database 
of Systematic Reviews. Issue 8 . doi:10.1002/14651858.cd012311

Glick, B. R., Patten, C. L., Holguin, G. and Penrose, D. M. 1999. Biochemical and Genetic Mechanisms Used by Plant Growth Promoting Bacteria. Imperial College Press, London. https://doi.org/10.1142/p130

Gontia-Mishra, I., Sapre, S. and Tiwari, S. 2017. Zinc solubilizing bacteria from the rhizosphere of rice as prospective modulator of zinc biofortification in rice. Rhizosphere, 3: 185-190. doi:10.1016/j.rhisph.2017.04.013

Govasmark, E. and Salbu, B. 2011. Translocation and re-translocation of selenium taken up from nutrient solution during vegetative growth in spring wheat. Journal of the Science of Food and Agriculture. 91(8): 13671372. doi:10.1002/jsfa.4387

Hassan Sayyari-Zahan, M., Singh Sadana, U., Steingrobe, B. and Claassen, N. 2009. Manganese efficiency and maganeseuptake kinetics of raya (Brassica juncea), wheat (Triticum aestivum), and oat (Avena sativa) grown in nutrient solution and soil. Journal of Plant Nutrition and Soil Science. 172(3): 425434. doi:10.1002/jpln.200800149

Hatfield, D. L., Tsuji, P. A., Carlson, B. A. and Gladyshev, V. N. 2014. Selenium and selenocysteine: roles in cancer, health, and development. Trends in Biochemical Sciences, 39(3): 112-120. doi:10.1016/j.tibs.2013.12.007

Hershfinkel, M. 2005. Zn2+, a dynamic signaling molecule. In: Molecular Biology of Metal Homeostasis and Detoxification (Ed. Tamàs, M.J., Martinoia, E.). Topics in Current Genetics, vol 14. Springer, Berlin, Heidelberg. https://doi.org/10.1007/ 4735_95

Hotz, C. and Brown, K.H. 2004. International Zinc Nutrition Consultative Group
(IZiNCG) Technical Document No. 1. Assessment of the Risk of Zinc Deficiency in Populations and Options for Its Control. Food and Nutrition Bulletin. 25: S94-S203.

Hurtado, E. K., Claussen, A. H. and Scott, K. G. 1999. Early childhood anemia and mild or moderate mental retardation. The American Journal of Clinical Nutrition. $\quad$ 69(1): 115-119. doi:10.1093/ajen/69.1.115

Jones, D.L. 1998. Organic acids in the rhizosphere - a critical review. Plant Soil. 205: 25-44. https://doi.org/10.1023/A:10043560073 12

Khalid, S., Asghar, H. N., Akhtar, M. J., Aslam, A. and Zahir, Z. A. 2015. Biofortification of iron in chickpea by plant growth promoting rhizobacteria. Pakistan Journal of Botany, 47(3): 1191-1194.

Khan, A. G. 2005. Role of soil microbes in the rhizospheres of plants growing on trace metal contaminated soils in phytoremediation. Journal of Trace Elements in Medicine and Biology. 18(4): $\quad 355-364 . \quad$ doi:10.1016/j. jtemb.2005.02.006

Khush, G. 2003. Productivity improvements in rice. Nutrition Reviews. 61(6 Pt 2): S114-s116. https://doi.org/10.131/ nr.2003.jun.S114

Krithika, S. and Balachandar, D. 2016. Expression of zinc transporter genes in rice as influenced by zinc-solubilizing Enterobacter cloacae strain ZSB14. Frontiers in Plant Science. 7: 446. doi:10.3389/fpls.2016.00446

Losi, M. E. and Frankenberger, W. T. 1997. Reduction of selenium oxyanions by Enterobacter cloacae SLD1a-1: isolation and growth of the bacterium and its expulsion of selenium particles. Applied and Environmental Microbiology. 63(8): 3079-3084. 
Mayer, J. E., Pfeiffer, W. H. and Beyer, P. 2008. Biofortified crops to alleviate micronutrient malnutrition. Current Opinion in Plant Biology. 11(2): 166170. doi:10.1016/j.pbi.2008.01.007

Murray-Kolb, L. E. 2013. Iron and brain functions. Current Opinion in Clinical Nutrition and Metabolic Care. 16(6): 703-707. doi: $10.1097 / \mathrm{mco} .0 \mathrm{~b} 013 \mathrm{e} 3283653 \mathrm{ef} 8$

Padash, A., Shahabivand, S., Behtash, F. and Aghaee, A. 2016. A practicable method for zinc enrichment in lettuce leaves by the endophyte fungus Piriformospora indica under increasing zinc supply. Scientia Horticulturae. 213: 367-372. doi:10.1016/j.scienta.2016.10.040

Prasad, B., Kumar, A., Singh, A. V. and Kumar, A. 2016. Plant growth and seed yield attributes as influenced by bacterial isolates under glass house. Progressive Research, 11 (IV): 25732576.

Prasanna, R., Nain, L., Rana, A. and Shivay, YS. 2016. In: Biofortification with Microorganisms: Present Status and Future Challenges (Ed. Singh, U., Praharaj, C., Singh, S., Singh, N.). Biofortification of Food Crops. Springer, New Delhi. https://doi. org/10.1007/978-81-322-2716-8_19

Prasanna, R., Bidyarani, N., Babu, S., Hossain, F., Shivay, Y. S. and Nain, L. 2015. Cyanobacterial inoculation elicits plant defense response and enhanced $\mathrm{Zn}$ mobilization in maize hybrids. Cogent Food \& Agriculture. 1 (1): 998507, doi:10.1080/ 23311932.2014.998507

Puig, S., Askeland, E. and Thiele, D. J. 2005. Coordinated remodeling of cellular metabolism during iron deficiency through targeted mRNA degradation. Cell. 120(1): 99-110. doi:10.1016/ j.cell.2004.11.032

Rana, A., Joshi, M., Prasanna, R., Shivay, Y. S. and Nain, L. 2012a. Biofortification of wheat through inoculation of plant growth promoting rhizobacteria and cyanobacteria. European Journal of Soil Biology. $\quad 50$ : 118-126. doi:10.1016/j.ejsobi.2012.01.005

Rana, A., Saharan, B., Nain, L., Prasanna, R. and Shivay, Y. S. 2012b. Enhancing micronutrient uptake and yield of wheat through bacterial PGPR consortia. Soil Science and Plant Nutrition. 58(5): 573582. doi: $10.1080 / 00380768.2012 .716750$

Rayman, M. P. 2012. Selenium and human health. The Lancet. 379 (9822): 12561268. doi:10.1016/s0140-6736 (11)61452-9

Salgueiro, M.J., Zubillaga, M., Lysionek, A., Cremaschi, G., Goldman, C.G., Caro, R., De Paoli, T., Hager, A., Weill, R. and Boccio, J. 2000. Zinc status and immune system relationship: a review. Biological Trace Element Research. 76 (3): 193-205.

Saravanan, V. S., Subramoniam, S. R. and Raj, S. A. 2003. Assessing in vitro solubilization potential of different zinc solubilizing bacterial (zsb) isolates. Brazilian Journal of Microbiology. 34:121-125.

Saravanan, V.S., Madhaiyan, M. and Thangaraju, M. 2007. Solubilization of zinc compounds by the diazotrophic, plant growth promoting bacterium Gluconacetobacter diazotrophicus. Chemosphere. 66(9): 1794-1798. doi:10.1016/j.chemosphere.2006.07.067

Schmidt, W. 1999. Mechanisms and regulation of reduction-based iron uptake in plants. New Phytologist. 141(1): $\quad 1-26 . \quad$ doi:10.1046/j.14698137.1999.00331.x

Shah, S., Ramanan, V. V., Singh, A. V. and Singh, A. K. 2018. Potential and prospect of plant growth promoting rhizobacteria in lentil. In: Scientific lentil production (Ed. Singh et al., 
2016). Satish Serial Publishing House, Delhi, India.

Shaikh, S. and Saraf, M. 2017. Biofortification of Triticum aestivum through the inoculation of zinc solubilizing plant growth promoting rhizobacteria in field experiment. Biocatalysis and Agricultural Biotechnology. 9: 120-126. doi:10.1016/j.bcab.2016.12.008

Shakeel, M., Rais, A., Hassan, M. N. and Hafeez, F. Y. 2015. Root associated Bacillus sp. improves growth, yield and zinc translocation for basmati rice (Oryza sativa) varieties. Frontiers in Microbiology. $\quad 6: \quad 1286$. doi:10.3389/fmicb.2015.01286

Sharma, A., Johri, B., Sharma, A. and Glick, B. 2003. Plant growth-promoting bacterium Pseudomonas sp. strain GRP3 influences iron acquisition in mung bean (Vigna radiata L. Wilzeck). Soil Biology and Biochemistry. 35(7): 887-894. doi:10.1016/s00380717(03)00119-6

Sharma, A., Shankhdhar, D. and SC, S. 2013. Enhancing grain iron content of rice by the application of plant growth promoting rhizobacteria. Plant, Soil and Environment. $\quad$ 59(2): $\quad 89-94$. doi:10.17221/683/2012-pse

Singh, A. V. and Goel, R. 2015. Plant growth promoting efficiency of Chryseobacterium sp. PSR10 on finger millet (Eleusine coracana). Journal of Global Biosciences. 4(6):2569-2575.

Singh, A. V. and Prasad, B. 2014. Enhancement of plant growth, nodulation and seed yield through Plant Growth Promoting Rhizobacteria in Lentil (Lens culinaris Medik cv. VL125). Int. J. Curr. Microbiol. Appl. Sci. 3(6): 614-622.

Singh, A. V., Agarwal, A. and Goel, R. 2010a. Comparative phosphate solubilization efficiency of two bacterial isolates and their effect on Cicer arietinum seeds in indigenous and alternative soil system. Environ. Ecol. 28: 1979-1983.

Singh, A. V., Chandra, R. and Reeta, G. 2013. Phosphate solubilization by Chryseobacterium sp. and their combined effect with $\mathrm{N}$ and $\mathrm{P}$ fertilizers on plant growth promotion. Archives of Agronomy and Soil Science. 59(5): 641651.

Singh, A. V., Prasad, B. and Goel, R. 2018. Plant Growth Promoting Efficiency of Phosphate Solubilizing Chryseobacterium sp. PSR 10 with Different Doses of N and P Fertilizers on Lentil (Lens culinaris var. PL-5) Growth and Yield. Int.J.Curr.Microbiol.App.Sci. $\quad 7(05)$ : 2280-2289.

Singh, A. V., Prasad, B. and Shah, S. 2010b. Screening Plant growth promotory rhizobacteria for improving seed germination and seedling vigor of lentil (Lens culinaris Medik). Environ. Ecol. 28: 2055-2058.

Singh, A. V., Prasad, B. and Shah, S. 2011. Influence of phosphate solubilizing bacteria for enhancement of plant growth and seed yield in lentil. J. Crop Weed. 7(1): 1-4.

Singh, A. V., Shah, S. and Prasad, B. 2010. Effect of phosphate solubilizing bacteria on plant growth promotion and nodulation in soybean (Glycine max (L.) Merr). J. Hill Agri. 1(1): 35-39.

Singh, J. and Singh, A. V. 2017. Microbial Strategies for Enhanced Phytoremediation of Heavy Metals Contaminated Soils. In: Environmental Pollutants and their Bioremediation Approaches (Ed. Bharagava, R. N.). Taylor \& Francis. CRC Press London, New York: 249-264.

Singh, J., Singh, A. V., Prasad, B. and Shah, S. 2017. Sustainable agriculture 
strategies of wheat biofortification through microorganisms. In: Wheat a premier food crop (Ed, Anil Kumar, Amarjeet Kumar and Birendra Prasad). Kalyani Publishers, New Delhi, India.

Singh, M.V. 2009. Micronutirent nutritional problems in soils in India and improvement for human and animal health. Indian J. Fertil. 5 (4): 11- 26.

St.Clair, S. B. and Lynch, J. P. 2010. The opening of Pandora's Box: climate change impacts on soil fertility and crop nutrition in developing countries. Plant and Soil. 335(1-2): 101-115. doi:10.1007/s11104-010-0328-Z

Sunithakumari, K., Padma Devi, S. N. and Vasandha, S. 2016. Zinc Solubilizing Bacterial Isolates from the Agricultural Fields of Coimbatore, Tamil Nadu, India. Current Science. 110(2): 196205. doi:10.18520/cs/v110/i2/196-205

Tariq, M., Hameed, S., Malik, K.A. and Hafeez, F.Y. 2007. Plant root associated bacteria for zinc mobilization in rice. Pakistan Journal of Botany. 39(1):245253
Tripathi, D. K., Singh, S., Singh, S., Mishra, S., Chauhan, D. K. and Dubey, N. K. 2015. Micronutrients and their diverse role in agricultural crops: advances and future prospective. Acta Physiologiae Plantarum. 37(7). doi:10.1007/s11738015-1870-3

United Nations System Standing Committee on Nutrition (UNSSCN). 2004. 5th Report on the World Nutrition Situation Nutrition for Improved Development Outcomes. SCN, Geneva.

Yao, T., Yasmin, S., Malik, K.A. and Hafeez, F.Y. 2008. Potential role of Rhizobacteria isolated from Northwestern China for enhancing wheat and oat yield. The Journal of Agricultural Science. $\quad 146(01): 49 \quad-\quad 56$. doi10.1017/S0021859607007356

Yasin, M., El-Mehdawi, A. F., Pilon-Smits, E. A. and Faisal, M. 2015. Seleniumfortified wheat: potential of microbes for biofortification of selenium and other essential nutrients. International Journal of Phytoremediation. 17(8): 777-786. doi:10.1080/15226514. 2014.987372

\section{How to cite this article:}

Viabhav Kumar Upadhayay, Ajay Veer Singh and Navneet Pareek. 2018. An Insight in Decoding the Multifarious and Splendid Role of Microorganisms in Crop Biofortification. Int.J.Curr.Microbiol.App.Sci. 7(06): 2407-2418. doi: https://doi.org/10.20546/ijcmas.2018.706.286 